\title{
Neurological Intensive Care for Acute Spinal Cord Injury Patients
}

\author{
Junseok W Hur, Dong-Hyuk Park, Jang-Bo Lee, Tai-Hyoung Cho, Jung-Yul Park
}

Department of Neurosurgery, College of Medicine, Korea University, Seoul, Korea

Received: September 13, 2018

Accepted: September 19, 2018

Published: October 10, 2018

\section{Corresponding Author:}

Junseok W Hur, M.D., Ph.D.

Department of Neurosurgery,

College of Medicine, Korea

University, 73 Inchon-ro,

Seongbuk-gu, Seoul 02841, Korea

Tel: +82-2-920-5729

Fax: +82-2-929-0629

E-mail: hurjune@gmail.com
The spinal cord injury (SCI) patients suffer various medical conditions at early period after injury. Methylprednisolone could be administrated for neurologic recovery but the potential side effects could be carefully considered. Besides limb motor and sensory deficits, SCI could affect various respiratory muscles as diaphragm, chest wall, and abdomen which leads to respiratory failure and mechanical ventilation. Sympathetic nerve denervation could lead hypotension and bradycardia. Volume supplement and cardiovascular constrictor could be considered. Prevention and treatment of pressure sore are essential and active pain control should be started from the intensive care unit.

Keywords: Spinal cord injury; Neurology; Intensive care; Shock; Methylprednisolone

\section{INTRODUCTION}

In the 21st century, remarkable advances in medicine have led to the development of treatments for many diseases. However, in the case of spinal cord injury (SCI), no clear solution has been found to restore neural damage even after pouring astronomical research costs into the development of new therapeutic drugs. However, it is encouraging that many empirical knowledge about acute critical care has accumulated. We will review the problems that may appear in patients immediately after injury of the spinal cord and summarize the latest knowledge for the treatment of patients in the neurological intensive care unit.

\section{CLINICAL MANIFESTATIONS}

\section{Motor and sensory deficit associated to injury level}

Spinal cord injury levels due to vertebral fractures may differ from spinal cord injury levels in actual clinical symptoms. For example, fracture and spinal cord compression at T5 level could induce neurologic symptom below T10. Therefore, accurate manifestation of neurologic disorders should be held. Depending on the level of nerve damage, the sensory and motor nerve damage ranges are determined. Furthermore, there are also other important points to consider due to injured level as respiratory function failure, reduced sympathetic nervous function, immunodeficiency and etc.

\section{Respiratory dysfunction}

Phrenic motor neurons are located at C3-5. Therefore, damage above the C5 may affect diaphragm function, resulting in hypercapnia, hypoxemia, and poor secretion clearance ${ }^{10,}$ ${ }^{17)}$. Injuries above $\mathrm{T} 11$ destroy innervation to the intercostal muscles leading to reduced chest wall motion, and injuries above L1 may interfere the innervation to the abdominal muscle ${ }^{1)}$. These neurological deficits can cause serious respiratory problems as dyspnea, apnea, and pneumonia. 


\section{Neurogenic shock}

Injury above T6 may affect sympathetic nerve and induce hypotension and bradycardia due to vasodilatation ${ }^{14)}$. For cervical lesion injury, $20 \%$ of patients show neurogenic shock and almost all patients show bradycardia ${ }^{8)}$. If there is no evidence of severe blood loss after trauma, neurogenic shock should be considered.

\section{NEUROGENIC INTENSIVE CARE}

\section{Methylprednisolone}

Three large randomized clinical trials named National Acute Spinal Cord Injury Studies (NASCIS) were performed. First trial published at 1984 concluded there is on significant difference between high dose methylprednisolone group (1,000-mg bolus and daily thereafter for ten days) and standard dose methylprednisolone group (100-mg bolus and daily thereafter for ten days $)^{2)}$. However, second trial adapted different infusion amount and type of methylprednisolone for the treatment group (a bolus of $30 \mathrm{mg}$ per kilogram of body weight, followed by infusion at $5.4 \mathrm{mg}$ per kilogram per hour for 23 hours) compared with naloxone administrated and placebo groups. This study concluded methylprednisolone have positive effect for the neurology recovery at 6 months period after injury ${ }^{3}$. The third NASCIS reported that patients recieving methylprednisolone within 3 hours of injury should be maintained on the treatment regimen for 24 hours and 48 hours when initiated 3 to 8 hours after injury. After this studies, high dose methylprednisolone has emerged as golden standard therapy for SCI. However, numerous comments against those have been poured out. Many scientist and physicians pointed out the statistical bias. Numerous retrospective and prospective studies refute the second and third NASCIS conclusion. They claimed there was no neurologic difference between high methylprednisolone group and placebo group, however, complications as gastrointestinal bleedings, wound infection, sudden death, pulmonary embolism seemed to be higher incidence for high dose methylprednisolone group ${ }^{6}$, ${ }^{11,15)}$. The two arguments are still conflicting and have been subject to contradictions that have been reversed according to the guidelines. Therefore, the authors recommends to use it according to the judgment of the clinician.

\section{Hemodynamics}

Maintenance of adequate blood supply to spinal cord is essential. Systemic hypotension should be avoided. Mean arterial pressure (MAP) between $85 \sim 90 \mathrm{mmHg}$ is recommended and systolic blood pressure under $90 \mathrm{mmHg}$ should be avoided for the first 7days post injury. Oxygen saturation should be maintained over $90 \%{ }^{9,16)}$. To prevent hypotension, lower extremity compression stockings, abdominal binding, volume augmentation (hydration, salt tablets or fludrocortisone), peripheral vasoconstriction (midodrine, ephedrine or droxidopa) should be considered ${ }^{12)}$.

\section{Respiration}

Depending on the level and degree of SCI, spontaneous breathing may not be smooth due to paralysis of the diaphragm, chest wall, and abdomen muscle. Therefore, if the patient's respiration pattern is paradoxical or if the saturation is continuously lowered to $90 \%$ or less, intubation and mechanical ventilation should be considered. Even if the breathing seems not so bad at early period, the oral secretions cannot be spit out well, so the airway obstruction often occurs. Theophylline could be helpful for respiratory function improvement ${ }^{5}$. There are studies that muscle spasticity could affect respiration function, and in this case, baclofen could be helpful ${ }^{4,13)}$.

\section{Pressure sores}

With sensory loss and immobilization due to motor deficit, pressure sores develop rapidly. Sore starts with focal infection and if not controlled well, immunodeficiency and systemic infection could occur and life threatening condition could be caused. Prevention is the most important treatment. Frequent position change, using anti-sore mattress are helpful. Once a sore develops, daily dressing, surgical debridement, vacuum suction could be considered ${ }^{7)}$.

\section{Pain control}

Active control of pain is essential from the beginning of SCI treatment. If the pain is not controlled, the prognosis of the patient is adversely affected. Additionally to nociceptive pain, neuropathic pain as allodynia and hyperalgesia occur almost $40 \%$ of SCI patients ${ }^{1)}$. NSAIDs, anticonvulsants, antidepressants, and opioids should be considered.

\section{CONCLUSION}

SCI patients suffer various medical conditions from the early period of injury. Meticulous clinical manifestations and appropriate intensive treatments are mandatory.

\section{CONFLICTS OF INTEREST}

No potential conflict of interest relevant to this article was reported. 


\section{ACKNOWLEDGEMENTS}

This study was supported in part by a grants of Korea University (K1809751, K1808641, K1722461), the Basic Science Research Program through the National Research Foundation of Korea (NRF) funded by the Ministry of Education, Science and Technology (NRF-2017R1D1A1B03035760) to Junseok W Hur.

\section{REFERENCES}

1. Ahuja CS, Wilson JR, Nori S, Kotter MR, Druschel C, Curt A, et al. Traumatic spinal cord injury. Nat Rev Dis Primers 2017;3:17018.

2. Bracken MB, Collins WF, Freeman DF, Shepard MJ, Wagner FW, Silten RM, et al. Efficacy of methylprednisolone in acute spinal cord injury. JAMA 1984;251:45-52.

3. Bracken MB, Shepard MJ, Collins WF, Holford TR, Young W, Baskin DS, et al. A randomized, controlled trial of methylprednisolone or naloxone in the treatment of acute spinal-cord injury: results of the Second National Acute Spinal Cord Injury Study. N Engl J Med 1990;322:1405-1411.

4. Britton DB, Goldstein BG, Jones-Redmond J, Esselman P . Baclofen pump intervention for spasticity affecting pulmonary function. J Spinal Cord Med 2005;28:343-347.

5. Ferguson GT, Khanchandani N, Lattin CD, Goshgarian HG . Clinical effects of theophylline on inspiratory muscle drive in tetraplegia. Neurorehabil Neural Repair 1999;13:191-197.

6. Galandiuk S, Raque G, Appel S, Polk HC Jr . The two-edged sword of large-dose steroids for spinal cord trauma. Ann Surg 1993;218:419.

7. Consortium for Spinal Cord Medicine Clinical Practice Guidelines . Pressure ulcer prevention and treatment following spinal cord injury: a clinical practice guideline for health-care professionals. J Spinal Cord Med 2001;24:S40.

8. Guly H, Bouamra O, Lecky F. The incidence of neurogenic shock in patients with isolated spinal cord injury in the emergency department. Resuscitation 2008;76:57-62.

9. Hadley M, Walters B, Grabb P, Oyesiku N, Przybylski G, Resnick D, et al. Guidelines for the management of acute cervical spine and spinal cord injuries. Neurosurgery 2002;49:407-498.

10. Autho . Physiology and pathophysiology of glottic reflexes and pulmonary aspiration: from neonates to adults: Seminars in respiratory and critical care medicine NIH Public Access, 2010, p554.

11. Kiwerski J Application of dexamethasone in the treatment of acute spinal cord injury. Injury 1993;24:457-460.

12. Krassioukov A, Eng JJ, Warburton DE, Teasell R, Team SCIRER. A systematic review of the management of orthostatic hypotension after spinal cord injury. Arch Phys Med Rehabil 2009;90:876-885.

13. Laffont I, Durand M-C, Rech C, De La Sotta AP, Hart N, Dizien $\mathrm{O}$, et al. Breathlessness associated with abdominal spastic contraction in a patient with $\mathrm{C} 4$ tetraplegia: a case report 1. Arch Phys Med Rehabil 2003;84:906-908.

14. Ploumis A, Yadlapalli N, Fehlings M, Kwon B, Vaccaro A . A systematic review of the evidence supporting a role for vasopressor support in acute SCI. Spinal Cord 2010;48:356.

15. Prendergast MR, Saxe JM, Ledgerwood AM, Lucas CE, Lucas WF . Massive steroids do not reduce the zone of injury after penetrating spinal cord injury. J Trauma 1994;37:576579; discussion 579-580.

16. Walters BC, Hadley MN, Hurlbert RJ, Aarabi B, Dhall SS, Gelb DE, et al. Guidelines for the management of acute cervical spine and spinal cord injuries: 2013 update. Neurosurgery 2013;60:82-91.

17. Autho . Effect of spinal cord injury on the respiratory system: basic research and current clinical treatment options 2007. Taylor \& Francis. 